\title{
Waktu Reproduksi Karang Lunak Sinularia flexibilis Quoy \& Gaimard (Octocorallia: Alcyonacea) Di Pulau Barrang Lompo, Kepulauan Spermonde,
} Sulawesi Selatan

\section{Spawning Time of Soft Coral Sinularia Flexibilis Quoy \& Gaimard (Octocorallia:} Alcyonacea) in Barrang Lompo Island, Spermonde Archipelago, South Sulawesi

\author{
Abdul Haris \\ Fakultas Ilmu Kelautan dan Perikanan Universitas Hasanuddin, Jl. Perintis Kemerdekaan km. 10 \\ Kampus Tamalanrea, Makassar 90245 \\ E-mail: haris_pagala@yahoo.co.id
}

\begin{abstract}
Sinularia flexibilis is a soft coral that has an economical value due to its farmacological substance. The aim of this research was to find out the spawning time and behaviour of Sinularia flexibilis by visual observation in its natural habitat and in hatchery. The result of this research revealed that the reproduction period of the Sinularia flexibilis occurred during May to September in each lunar phase. However, it was found that during a new moon phase, the reproduction activity had the highest percentage of colony for every lunar phase. Spawning behavior of the Sinularia flexibilis was that a bunch of eggs and the sperm were separately spawned from the mouth by fast contraction in a short period of time.
\end{abstract}

Key words: Sinularia flexibilis, spawning time, Barrang Lompo Island

\begin{abstract}
Abstrak
Sinularia fleksibilis adalah salah satu jenis karang lunak yang memiliki nilai ekonomis karena mengandung senyawa yang bersifat farmakologik. Penelitian ini bertujuan mengetahui waktu reproduksi dan tingkah laku memijah karang lunak Sinularia fleksibilis dengan metode pengamatan langsung di alam dan di hatchery. Hasil penelitian menunjukkan bahwa waktu reproduksi karang lunak $S$. fleksibilis berlangsung pada bulan Mei sampai September pada setiap fase bulan, aktivitas reproduksi pada fase bulan gelap memiliki persentase jumlah koloni tertinggi untuk setiap siklus bulannya selama pengamatan. Tingkah laku memijah karang lunak Sinularia fleksibilis dilakukan dengan cara kumpulan telur dan sperma disemprotkan secara terpisah dari mulut melalui kontraksi yang cepat dalam periode waktu yang singkat.
\end{abstract}

Kata kunci: Sinularia fleksibilis, waktu reproduksi, Pulau Barrang Lompo

Diterima: 31 Agustus 2009, disetujui: 10 Juni 2010

\section{Pendahuluan}

Karang lunak Sinularia flexibilis adalah suatu jenis karang lunak yang memiliki nilai ekonomis tinggi yang berasal dari ekosistem terumbu karang. Karang lunak mengandung senyawa-senyawa bioaktif yang telah telah diketahui mempunyai sifat-sifat farmakologik (Kawaroe et al., 2008). Senyawa-senyawa bioaktif yang telah diisolasi dari karang lunak ini antara lain: sinulariolide, sinularin, dihydrosinularin (Tursch et al., 1978; Michalek dan Bowden, 1997), sandensolide monoacetate, flexibolide (Anjaneyulu et al., 1997), cembranoid diterpenes, sinuflexolide, dihydrosinuflexolide, sinuflexibilin (Duh et al., 1998), diterpenes flexibilide (Aceret et al., 1998), 11-epi-sinulariolide acetate, 11dehydrosinulariolide, sinulariolide (Hsieh et al., 2003). Senyawa-senyawa tersebut memiliki aktivitas sebagai senyawa antimikroba, bersifat sitotoksik, dan berpotensi sebagai senyawa antikanker.

Karang lunak terancam keberadaannya, karena sebagaian besar habitatnya telah mengalami kerusakan yang cukup serius. 
Menurut Suharsono (1999), dari 416 lokasi terumbu karang di 43 daerah yang tersebar di seluruh perairan Indonesia hanya $6,49 \%$ dalam kondisi sangat baik, $24,28 \%$ dalam kondisi baik, $28,61 \%$ kondisi sedang dan $40,62 \%$ buruk. Selain itu, karang lunak ini juga telah terancam keberadaannya akibat semakin intensif pengambilan secara langsung dari alam untuk tujuan penelitian biomedik dan ekologi.

Pemanfaatan karang lunak cenderung meningkat dari tahun ke tahun, terutama untuk mencari senyawa bioaktif baru dan memproduksi senyawa bioaktif tertentu. Spesimen untuk pemanfaatan tersebut, diambil secara langsung dari alam dan belum ada dari hasil budidaya. Hal ini dilakukan secara terus menerus dapat menurunkan populasi secara signifikan bahkan bisa mengakibatkan kepunahan. Oleh karena itu, untuk pemanfaatan yang berkesinambungan, kelestarian karang lunak ini perlu dijaga dan dipertahankan (Kawaroe et al., 2008).

Untuk mengendalikan laju kerusakan habitat, laju pengambilan karang lunak dan mencegah tangkap lebih (overfishing), perlu dilakukan upaya budidaya. Pengembangan budidaya diarahkan untuk memproduksi ekstrak kasar dan fraksi ekstrak skala besar atau skala industri dan menyediakan bibit/anakan untuk restocking pada kawasan terumbu karang yang rusak. Pengembangan budidaya untuk memproduksi ekstrak kasar dan fraksi ekstrak hanya dapat dilakukan bila aspek biologi reproduksi karang lunak ini diketahui dengan baik, termasuk waktu reproduksinya (Kawaroe et al., 2008).

Penelitian ini bertujuan untuk mengetahui waktu reproduksi karang lunak Sinularia flexibilis yang didasarkan pada fase bulan, dan juga untuk mengetahui tingkah laku reproduksi nya, baik di alam maupun di "hatchery".

\section{Metode Penelitian}

\section{Lokasi dan Waktu Penelitian}

Penelitian ini dilaksanakan selama kurang lebih 7 bulan yang dimulai dari bulan Maret 2005 sampai dengan September 2005. Pengamatan dilakukan di sekitar perairan terumbu karang Pulau Barrang Lompo, Makassar dan di Hatchery Marine Station FIKPUNHAS. Pengamatan dilakukan menurut penanggalan bulan (bulan Qomariah). Pengamatan waktu bereproduksi dilakukan menurut fase bulan selama satu siklus bulan.

\section{Bahan dan Alat}

Bahan dan peralatan yang digunakan dalam penelitian ini terdiri dari bahan dan peralatan yang digunakan di lapangan, laboratorium dan pembenihan (hatchery) (Tabel 1).

\section{Prosedur Penelitian}

Waktu reproduksi (jam, durasi, dan periode reproduksi) dan tingkah laku reproduksi dilakukan dengan dua cara, yaitu: pengamatan lapangan dan pengamatan di hatchery. Pengamatan waktu reproduksi dilakukan berdasarkan siklus bulan, karena menurut Richmond dan Jokiel (1984); Wallace (1985), Babcock et al., (1986); Hunter (1988); Hunter (1990); Glynn et al., (1991); Ward (1992) dan McGuire (1998), sebagian besar karang memijah atau berplanulasi terjadi sekitar bulan baru dan bulan purnama.

Tabel 1. Bahan dan Peralatan yang Digunakan dalam Penelitian.

\begin{tabular}{cll}
\hline \hline No. & \multicolumn{1}{c}{ Bahan/Alat } & \multicolumn{1}{c}{ Keterangan } \\
\hline \hline 1. & Karang lunak Sinularia flexibilis & Hewan uji \\
2. & Scuba diving & $\begin{array}{l}\text { Untuk penyelaman dalam mengamati waktu dan tingkah laku pemijahan } \\
\text { karang }\end{array}$ \\
3. & Senter Selam & Untuk mengamati waktu dan tingkah laku pemijahan karang pada \\
& & malam hari \\
4. & Bak pemeliharaan & Tempat memijahkan karang \\
5. & Pompa air & Memompa air \\
6. & Aerator & Oksigenasi di bak pemeliharaan \\
7. & Water Quality Checker & Mengukur parameter kualitas air \\
\hline \hline
\end{tabular}




\section{Pengamatan Lapangan}

Pengamatan dilakukan dengan penyelaman pada malam hari, sesaat setelah matahari terbenam. Penentuan penyelaman malam dilakukan berdasarkan siklus bulan. Oleh karena itu, penyelaman dilakukan selama 3-4 hari sebelum dan sesudah bulan baru, bulan 1/4, bulan purnama, dan bulan $3 / 4$ selama satu siklus bulan. Jumlah sampel karang lunak $S$. flexibilis yang diamati setiap kali pengamatan adalah 10 koloni

\section{Pengamatan Laboratorium (Hatchery)}

Dilakukan dengan cara menempatkan 8 koloni karang dalam bak pemeliharaan. Selama masa pemeliharaan dilakukan pergantian air setiap hari. Sebelum dilakukan pengamatan, koloni-koloni karang diaklimatisasi selama kurang lebih satu bulan. Prosedur pengamatan dan pengukuran sama dengan yang dilakukan pada pengamatan lapangan. Sampel karang lunak $S$. flexibilis yang digunakan untuk pengamatan di laboratorium koloninya berdiameter $20-30 \mathrm{~cm}$.

\section{Analis Data}

Waktu reproduksi (jam, durasi, dan periode reproduksi) dan tingkah laku memijah disajikan dalam bentuk tabel dan dianalisis secara deskriptif. Jumlah koloni karang yang memijah pada setiap fase bulan dinyatakan dalam persen (\%), durasi reproduksi dinyatakan dalam menit per malam, dan periode reproduksi dinyatakan dalam hari per koloni. Hasil penelitian pada tabel disajikan dalam rata-rata \pm Standar Error (SE).

\section{Hasil dan Pembahasan}

\section{Waktu Reproduksi}

\section{Pengamatan di Alam}

Waktu reproduksi karang lunak $S$. flexibilis yang meliputi jam, durasi, periode, dan tingkah laku reproduksi dari 10 koloni yang diamati di lapangan (in-situ), disajikan pada Tabel 2.

Hasil pengamatan di lapangan menunjukan bahwa waktu pemijahan pada fase bulan gelap dan fase bulan $3 / 4$ memiliki kisaran yang lebih lama dibanding dengan fase bulan purnama dan fase bulan $1 / 4$ yang memiliki kisaran yang sempit. Selain itu dari 10 koloni yang diamati memperlihatkan bahwa pada fase bulan gelap semua koloni karang melakukan aktivitas pemijahan $(100 \%)$, pada fase bulan $3 / 4$ hanya $80 \%$, sedangkan pada fase bulan $1 / 4$ dan bulan purnama $70 \%$ (Tabel 2). Hasil penelitian ini berbeda dengan yang didapatkan oleh Vermeij et al., (2003). Hasil penelitiannya didapatkan bahwa karang Madracis senaria dan Madracis mirabilis memiliki aktivitas pemijahannya sebesar $67 \%$, M. decactis dan M. pharensis $20 \%$, dan aktivitas pemijahannya berlangsung pada bulan September sampai November selama musim gugur. Perbedaan waktu atau bulan-bulan pemijahan karang yang diteliti ini dengan penelitian yang dilakukan oleh Vermeij et al., (2003) disebabkan oleh perbedaan faktor-faktor lingkungan, terutama suhu perairan antara daerah tropis dan subtropis. Menurut Harriott (1983), Richmond dan Jokiel (1984), Babcock et al., (1986), Hunter (1988), Harrison dan Wallace (1990), Richmond dan Hunter (1990), dan Szmant (1991) menyatakan bahwa perubahan suhu perairan oleh perubahan musim dapat menentukan waktu siklus reproduksi tahunan (gametogenesis) pada karang dan juga menjadi isyarat untuk pemijahan.

Pada Tabel 2 juga diperlihatkan bahwa waktu pemijahan karang lunak S. flexibilis pada setiap fase bulan terjadi setelah matahari terbenam pada kisaran jam 18.35-20.55. Hasil penelitian ini relatif berbeda dengan yang didapatkan oleh Harrison et al., (1984) di bagian tengah Great Barrier Reef, yang mendapatkan waktu pemijahan karang Acropora tenuis pada sekitar pukul 19.00, Galaxea spp. pada pukul 19.45, dan Acroporidae dan Faviidae pada sekitar pukul 20.00-23.00.

Pemijahan karang lunak $S$. flexibilis terjadi pada malam ke-2 sampai malam ke-5 dengan puncak pemijahan terjadi pada malam ke-3 dan ke-4, sedangkan pada malam ke-1, ke-6 dan ke-7 seluruh koloni yang teramati sama sekali tidak memperlihatkan aktivitas pemijahan. Selain itu diketahui pula bahwa pada fase bulan gelap seluruh koloni pada malam ke-4 memperlihatkan aktivitas pemijahan (Tabel 3). Hasil penelitian ini berbeda dengan penelitian yang dilakukan oleh Babcock et al., (1986), yang 
mendapatkan pemijahan karang pada malam ke3 sampai ke-6 setelah bulan purnama dengan puncak pemijahan terjadi pada malam ke-3 sampai ke-5 di Pulau Magnetic dan Orpheus. Perbedaan juga terjadi dengan penelitian yang dilakukan oleh Mendes dan Woodley (2002), yang mendapatkan pemijahan karang pada malam ke-6 dan ke-8 setelah bulan purnama pada bulan Agustus atau September atau keduanya di Jamaika.

Pada fase bulan gelap, durasi reproduksi setiap koloni $S$. flexibilis lebih lama daripada durasi produksi pada fase bulan $1 / 4$, fase bulan purnama, dan fase bulan $3 / 4$, sedangkan periode reproduksi berkisar antara 1-3 hari per koloni, kecuali pada fase bulan $1 / 4$ yang periode reproduksinya berkisar 1-2 hari per koloni (Tabel 4). Pada Tabel 4 juga terlihat bahwa durasi pemijahan karang lunak $S$. flexibilis pada setiap fase bulan berbeda-beda antara satu dan yang lainnya. Pada fase bulan gelap rata-rata 58,650 menit, fase bulan $1 / 4$ rata-rata 20.545 menit, fase bulan purnama rata-rata 43,667 menit, dan fase bulan $3 / 4$ rata-rata 53,750 menit. Hasil penelitian ini relatif berbeda dengan yang dilakukan oleh Rani dan Jompa (2005) yang mendapatkan durasi pemijahan karang Pocillopora verrucosa di Pulau Barrang Lompo, Makassar rata-rata 4,17 menit untuk pengeluaran sperma dan rata-rata 6,43 menit untuk pelepasan telur. Perbedaan durasi pemijahan antara karang lunak $S$. flexibilis dengan karang batu Pocillopora verrucosa disebabkan perbedaan jenis diantara keduanya. S. flexibilis adalah karang dari subkelas Octocorallia, sedangkan Pocillopora verrucosa adalah karang dari subkelas Hexacorallia. Selain itu, secara morfologi $S$. flexibilis memiliki polip yang sangat kecil, sedangan Pocillopora verrucosa memiliki polip yang relatif besar.

\section{Pengamatan di Hatchery}

Pengamatan waktu reproduksi di hatchery dilakukan dengan terlebih dahulu mengambil karang lunak $S$. flexibilis dari alam sebanyak 8 koloni, kemudian menempatkannya pada bak pemeliharaan. Sebelum pengamatan, terlebih dahulu dilakukan aklimatisasi koloni-koloni karang lunak tesebut selama \pm 1 bulan.

Hasil pengamatan di hatchery diketahui bahwa tidak semua koloni karang lunak $S$. flexibilis melakukan aktivitas reproduksi. Pada fase bulan gelap koloni yang dikumpulkan melakukan aktivitas pemijahan sebanyak $75 \%$, fase bulan $3 / 450 \%$, fase bulan purnama $37.5 \%$ dan fase bulan $1 / 425 \%$, dengan waktu pemijahan pada jam 18.40-20.57 (Tabel 5). Persentase karang yang melakukan aktivitas pemijahan antara di lapangan dengan di hatchery relatif berbeda. Persentase karang yang memijah di lapangan berkisar antara 70-100\% (Tabel 2), sedangkan di hatchery hanya berkisar $25-75 \%$ (Tabel 5). Perbedaan persentase jumlah karang yang memijah antara di lapangan dengan di hatchery disebabkan oleh perbedaan kondisi lingkungan dikedua tempat tersebut. Di lapangan kondisi perairan relatif stabil dengan kedalaman air yang lebih dalam (sekitar 5 meter), sedangkan di hatchery terjadi sebaliknya dengan kedalaman air di bak-bak pemeliharaan hanya sekitar $50 \mathrm{~cm}$.

Pada Tabel 5 terlihat bahwa waktu pemijahan yang didapatkan di Hatchery relatif sama dengan waktu pemijahan di lapangan. Waktu pemijahan karang di lapangan antara jam 18.35-20.55 (Tabel 2), sedangkan di hatchery jam 18.40-20.57. Kesamaan relatif waktu pemijahan antara di lapangan dengan di hatchery menunjukkan bahwa waktu pemijahan karang bersifat konsisten. Menurut Harrison et al., (1984), Shlesinger dan Loya (1985), Babcock et al., (1986), Szmant (1986) waktu pemijahan pada kebanyakan spesies karang berlangsung antara menjelang malam sampai tengah malam, dan waktu pemijahan pada umumnya bersifat konsisten dari tahun ke tahun.

Pada Tabel 6 diperlihatkan bahwa pemijahan karang lunak $S$. flexibilis terjadi pada malam ke-3 sampai malam ke-5, dengan puncak pemijahan terjadi pada malam ke-4, sedangkan malam ke-1, ke-2, ke-6 dan ke-7 (2 hari sebelum dan setelah pada fase bulan) seluruh koloni yang teramati sama sekali tidak memperlihatkan aktivitas pemijahan. Kondisi ini berbeda dengan yang didapatkan di lapangan. Malam-malam pemijahan di lapangan terjadi pada malam ke-2 sampai malam ke-6 pada fase bulan gelap, malam ke-3 sampai malam ke-4 pada fase bulan $1 / 4$, malam ke-2 sampai malam ke-4 pada fase bulan purnama, dan malam ke-3 sampai malam ke-5 pada fase bulan 3/4 (Tabel 3). Selain itu, persentase pemijahan karang pada malam-malam 
pemijahan antara di lapangan dengan di hatchery juga berbeda. Persentase pemijahan di lapangan berkisar antara 30-100\% (Tabel 3), sedangkan di hatchery hanya berkisar 25-62,5\% (Tabel 6).

Pada Tabel 7 diperlihatkan bahwa pada fase bulan gelap karang lunak $S$. flexibilis memiliki durasi reproduksi yang lebih lama, dengan nilai rata-rata 52,111 menit setiap malamnya dengan kisaran periode reproduksi 1-3 hari dibanding fase bulan lainnya. Hasil pengamatan ini juga diperkuat seperti pengamatan yang dilakukan di alam.

Tabel 2. Hasil Pengamatan Pemijahan in-situ Koloni Karang Lunak S. flexibilis menurut Fase Bulan Qomariah di Alam.

\begin{tabular}{cccc}
\hline \hline Fase Bulan & Jumlah Koloni & Persentase Pemijahan (\%) & Waktu Pemijahan (menit) \\
\hline \hline Gelap & 10 & 100 & $19.05-20.51$ \\
$1 / 4$ & 10 & 70 & $18.35-19.15$ \\
Purnama & 10 & 70 & $19.30-20.55$ \\
3 / 4 & 10 & 80 & $19.00-20.55$ \\
\hline \hline
\end{tabular}

Tabel 3. Persentase Koloni Karang Lunak S. flexibilis yang Memijah pada Setiap Fase Bulan di Alam.

\begin{tabular}{cccccccc}
\hline \hline \multirow{2}{*}{ Fase Bulan } & \multicolumn{7}{c}{ Persentase Pemijahan (\%) } \\
\cline { 2 - 8 } & Malam 1 & Malam 2 & Malam 3 & Malam 4 & Malam 5 & Malam 6 & Malam 7 \\
\hline \hline Gelap & - & 30 & 40 & 100 & 30 & - & - \\
1 / 4 & - & - & 50 & 60 & - & - & - \\
Purnama & - & 30 & 50 & 40 & - & - & - \\
3 / 4 & - & - & 40 & 70 & 50 & - & - \\
\hline \hline
\end{tabular}

Tabel 4. Durasi dan Periode Pemijahan Koloni Karang Lunak S. flexibilis Selama Pengamatan di Alam (In-Situ).

\begin{tabular}{ccccc}
\hline \hline \multirow{2}{*}{ Fase Bulan } & \multicolumn{2}{c}{ Durasi Reproduksi (Menit/Malam) } & \multicolumn{2}{c}{ Periode Reproduksi (Hari/Koloni) } \\
\cline { 2 - 5 } & Kisaran & Rata-Rata \pm SE & Kisaran & Rata-Rata \pm SE \\
\hline \hline Gelap & $24-99$ & $58,650 \pm 9,821$ & $1-3$ & $2,000 \pm 0,596$ \\
$1 / 4$ & $12-35$ & $20,545 \pm 4,475$ & $1-2$ & $1,571 \pm 0,404$ \\
Purnama & $18-80$ & $43,667 \pm 9,780$ & $1-3$ & $1,714 \pm 0,571$ \\
3 / 4 & $35-85$ & $53,750 \pm 7,311$ & $1-3$ & $2,000 \pm 0,535$ \\
\hline \hline
\end{tabular}

$( \pm \mathrm{SE}=$ Standar Error $)$

Tabel 5. Hasil Pengamatan Pemijahan in-situ Koloni Karang Lunak S. flexibilis pada Setiap Fase Bulan di Hatchery.

\begin{tabular}{cccc}
\hline \hline Fase Bulan & Jumlah Koloni & Persentase Pemijahan (\%) & Waktu Pemijahan \\
\hline \hline Gelap & 8 & 75 & $18.40-20.57$ \\
$1 / 4$ & 8 & 25 & $18.40-19.28$ \\
Purnama & 8 & 37,5 & $18.50-20.05$ \\
$3 / 4$ & 8 & 50 & $18.45-20.20$ \\
\hline \hline
\end{tabular}

Tabel 6. Persentase Koloni Karang Lunak S. flexibilis yang Memijah pada Setiap Fase Bulan di Hatchery.

\begin{tabular}{cccccccc}
\hline \hline \multirow{2}{*}{ Fase Bulan } & \multicolumn{7}{c}{ Persentase Pemijahan (\%) } \\
\cline { 2 - 8 } & Malam 1 & Malam 2 & Malam 3 & Malam 4 & Malam 5 & Malam 6 & Malam 7 \\
\hline \hline Gelap & - & - & 25 & 62,5 & 25 & - & - \\
1 / 4 & - & - & - & 25 & - & - & - \\
Purnama & - & - & - & 37,5 & 25 & - & - \\
$3 / 4$ & - & - & 25 & 37,5 & 25 & - & - \\
\hline \hline
\end{tabular}

Tabel 7. Durasi dan Periode Pemijahan Koloni Karang Lunak S.flexibilis Selama Pengamatan di Hatchery.

\begin{tabular}{ccccc}
\hline \hline \multirow{2}{*}{ Fase Bulan } & \multicolumn{2}{c}{ Durasi Reproduksi (Menit/Malam) } & \multicolumn{2}{c}{ Periode Reproduksi (Hari/Koloni) } \\
\cline { 2 - 5 } & Kisaran & Rata-Rata \pm 2 SE & Kisaran & Rata-Rata $\pm 2 S E$ \\
\hline \hline Gelap & $22-82$ & $52,111 \pm 15,558$ & $1-3$ & $1,500 \pm 0,683$ \\
$1 / 4$ & $28-33$ & $30,500 \pm 5,000$ & 1 & $1,000 \pm 0,000$ \\
Purnama & $33-55$ & $44,600 \pm 6,974$ & $1-2$ & $1,667 \pm 0,667$ \\
3 / 4 & $35-65$ & $45,286 \pm 9,204$ & $1-3$ & $1,750 \pm 0,500$ \\
\hline \hline
\end{tabular}

( \pm SE $=$ Standar Error $)$ 


\section{Tingkah Laku Memijah}

Tingkah laku memijah spesies karang menurut Babcock et al., (1986) dibedakan atas 3 tipe, yaitu : 1) Tipe I, merupakan tingkah laku yang umum dalam pemijahan, yaitu koloni dengan lambat melepaskan kemasan gamet melalui polip selama periode 5-50 menit. Pada koloni hermafrodit telur dan sperma dalam setiap polip terbungkus dalam satu atau lebih kemasan telur sperma yang kompak. 2) Tipe II, gamet disemprotkan dari mulut melalui kontraksi yang cepat dan meliputi sebagian atau seluruh koloni setelah mengalami suatu periode persiapan yang singkat. Proses ini berulang sekali atau beberapa kali dalam suatu rangkaian yang cepat. Gamet disemprotkan dalam dua bentuk, yaitu sebagai kemasan telur sperma atau terpisah sebagai kumpulan telur dan sperma. 3) Tipe III, gamet baik yang diperas keluar atau disemprotkan dengan keras oleh polip terlihat mengapung secara pasif di luar celah mulut.

Berdasarkan hasil pengamatan di lapangan (in-situ) dan di bak perlakuan (di hatchery) diketahui bahwa tingkah laku memijah karang lunak S. flexibilis termasuk tipe II (Babcock et al., 1986), yaitu telur dan sperma disemprotkan secara terpisah melalui mulut polip dengan suatu kontraksi yang cepat. Proses tersebut berlangsung seketika dan terlihat hanya 1-2 kali pada saat pengamatan untuk setiap koloni yang melakukan aktivitas pemijahan. Hasil ini juga dapat diperkuat dengan hasil histologi pada penelitian yang lain, di mana kehadiran telur dan sperma umumnya terdapat pada polip yang berbeda.

\section{Simpulan dan Saran}

\section{Simpulan}

Waktu reproduksi karang lunak $S$. flexibilis berlangsung pada bulan Mei September pada setiap tahunnya. Aktivitas reproduksi pada fase bulan gelap memiliki persentase jumlah koloni tertinggi. Tingkah laku memijah karang lunak S. flexibilis termasuk dalam tipe II, yaitu kumpulan telur dan sperma disemprotkan secara terpisah dari mulut melalui kontraksi yang cepat dalam periode waktu yang singkat.

\section{Saran}

Perlu dilakukan penelitian lanjutan untuk mencoba pembenihan dan pembesaran larvanya dengan perlakuan tertentu terhadap lingkunganya, serta pemberian pakan alami.

\section{Ucapan Terima Kasih}

Terima kasih kepada DP2M-DIKTI, Departemen Pendidikan Nasional RI yang telah memberikan bantuan dana penelitian melalui program Hibah Bersaing.

\section{Daftar Pustaka}

Aceret, T.L., Coll, J.C., Uchio, Y. dan Sammarco, P.W. 1998. Antimicrobial Activity of the Diterpenes Flexibilide and Sinulariolide Derived from Sinularia Flexibilis Quoy and Gaimard 1833 (Coelenterata: Alcyonacea, Octocorallia). Comp Biochem Physiol C Pharmacol Toxicol Endocrinol., 120 (1): 121-6.

Anjaneyulu, A.S.R., Sagar, K.S. dan Rao, G.V. 1997. New Cembranoid Lactones from the Indian Ocean Soft Coral Sinularia Flexibilis. J. Nat. Prod., 60 (1): 9-12.

Babcock, R.C., Bull, G.D., Harrison, P.L., Heyward, A.J., Oliver, J.K., Wallace, C.C. dan Willis, B.L. 1986. Synchronous Spawnings of 105 Sclrecatinian Coral Species on the Great Barrier Reef. Mar. Biol., 90: 379-394.

Duh, C.Y., Wang, S.K., Tseng, H.K., Sheu, J.H. dan Chiang, M.Y. 1998. Novel Cytotoxic Cembranoids from the Soft Coral Sinularia Flexibilis. J. Nat. Prod., 61 (6): 844-7.

Glynn, P.W., Gassman, N.J., Eakin, C.M., Cortés, J., Smith, D.B. dan Guzmán, H.M. 1991. Reef Coral Reproduction in the Eastern Pacific: Costa Rica, Panama, and Galapagos Islands (Ecuador). I. Pocilloporidae. Mar. Biol., 109: 355-368.

Glynn, P.W., Colley, S.B., Eakin, C.M., Smith, D.B., Cortés, J., Gassman, N.J., Guzmán, H.M., Del Rosario, J.B. dan Feingold, J.S. 1994. Reef Coral Reproduction in the Eastern Pacifik: Costa Rica, Panama, and Galápagos Islands (Ecuador). II. Poritidae. Mar. Biol., 118: 191-208.

Harriott, V.J. 1983. Reproductive Seasonality, Settlement and Post Settlement of Pocillopora Damicornis (Linnaeus) at Lizard Island, Great Barrier Reef. Coral Reefs, 2: 151-157. 
Harrison, P.L., Babcock, R.C., Bull, G.D., Oliver, J.K., Wallace, C.C. dan Willis, B.L. 1984. Mass Spawning in Tropical Reef Corals. Science, 223: $1186-1189$.

Harrison, P.L. dan Wallace, C.C. 1990. Reproduction, Dispersal and Recruitment of Scleractinian Corals: In: Dubinsky (Eds.). Coral Reefs. Ecosystems of The World 25. Pp. 132-207. Amsterdam, Oxford, New York, Tokyo: Elsevier.

Hsieh, P.W., Chang, F.R., McPhail, A.T., Lee, K.H. dan Wu, Y.C. 2003. New Cembranolide Analogues from the Formosan Soft Coral Sinularia Flexibilis and Their Cytotoxicity. Nat Prod Res., 17 (6): 409-18.

Hunter, C.L. 1988. Environmental Cues Controling Spawning in Two Hawaiian Corals, Montipora verrucosa and $M$. dilatata. Proc $6^{\text {th }}$ Int Coral Reef Symp. Australia, 2: 727-732.

Kawaroe, M., Dedi, S. dan Rahmadsyah, D.S. 2008. Periode Pemijahan Spons Aaptos aaptos (Porifera: Demospongia) di Perairan Pulau Pari, Kepulauan Seribu, DKI Jakarta. Biota, 13 (2): 68-74.

McGuire, M.P. 1998. Timing of Larval Release by Porites Astreoides in the Northern Florida Keys. Coral Reefs, 17: 369-375.

Mendes, J.M. dan Woodley, J.D. 2002. Timing of Reproduction in Montastraea Annularis: Relationship to Environmental variables. Mar Ecol. Prog. Ser., 227: 241-251.

Michalek, A. dan Bowden, B.F. 1997. A Natural Algicide from Soft Coral Sinularia Flexibilis (Coelenterata, Octocorallia, Alcyonacea). J. of Chemical Ecology., 23 (2): 259-272; 34 ref.

Rani, C. dan Jompa, J. 2005. Tingkah Laku Memijah Karang Acropora Nobilis dan Pocillopora Verrucosa Di Terumbu Karang Tropik Pulau Barranglompo, Makassar. Torani, 15 (4): 221-228.
Richmond, R.H. dan Hunter, C.L. 1990. Reproduction and Recruitment of Corals: Comparisons Among the Caribbean, the Tropical Pacific, and the Red Sea. Mar. Ecol. Prog. Ser., 60: 185-203.

Richmond, R.H. dan Jokiel, P.L. 1984. Lunar Periodicity in Larva Release in the Reef Coral Pocillopora Damicornis at Enewetak and Hawaii. Bull. Mar. Sci., 34 (2): 280-287.

Shlesinger, Y. dan Loya, Y. 1985. Coral Community Reproductive Patterns: Red Sea Versus the Great Barrier Reef. Science, 228: 1333-1335.

Suharsono. 1999. Condition of Coral Reef Ressources in Indonesia. Oceanology Research and Development Centre (Pusat Penelitian dan Pengembangan Oseanologi, LIPI).

Szmant, A.M. 1986. Reproductive Ecology of Caribbean Reef Corals. Coral Reefs, 5: 43-54.

Szmant, A.M. 1991. Sexual Reproduction by the Caribbean Reef Corals Montastrea annularis and $M$. cavernosa. Mar. Ecol. Prog. Ser., 74: 13-25.

Tursch, B., Braekman, J.C., Dalose, D. dan Kasin, M. 1978. Terpenoid from Coelenterata. In: Scheuuer, P.J. (Eds.). Marine Natural Products, Chemical and Biological Perpectures II Academic Press N.Y: 247-296.

Vermeij, M.J.A., Sampayo, E., Bröker, K. dan Bak, R.P.M. 2003. Variation in Planulae Release of Closely Relatedcoral Species. Mar. Ecol. Prog. Ser., 247: 75-84.

Wallace, C.C. 1985. Reproduction, Recruitment and Fragmentation in Nine Sympatric Species of the Coral Genus Acropora. Mar. Biol., 88: 217-233.

Ward, S. 1992. Evidence for Broadcast Spawning as well as Brooding in the Scleractinian Coral Pocillopora Damicornis. Mar. Biol., 112: 641-646. 